\title{
A formação de onomatopeias nos quadrinhos nacionais: questões ortográficas e fonológicas
}

\author{
Natália Cristine Prado \\ Fundação Universidade Federal de Rondônia (UNIR), Porto Velho, Rondônia, Brasil \\ natalia.prado@unir.br
}

DOI: http://dx.doi.org/10.21165/el.v46i1.1586

\begin{abstract}
Resumo
O objetivo deste estudo é investigar onomatopeias a partir dos quadrinhos brasileiros, observando a relação entre fonologia e ortografia que se estabelece nesses vocábulos. Para este trabalho, foram observadas 60 histórias em quadrinhos a partir das revistas "Turma da Mônica” (Mônica, Magali, Cascão, Cebolinha, Chico Bento e Turma da Mônica) e coletadas 162 onomatopeias. Após a coleta desses dados, passamos a observar a relação entre ortografia e fonologia. Pudemos observar, neste estudo, que a escrita das onomatopeias passa por um processo de estilização da ortografia - muitas vezes com o intuito de trazer elementos prosódicos para o vocábulo, como, por exemplo, volume e duração. Outro fato interessante é que as onomatopeias podem apresentar, inclusive, sequências que, apesar de permitidas pelo molde silábico da língua portuguesa, acabam restritas a poucos usos.
\end{abstract}

Palavras-chave: onomatopeia; ortografia; fonologia.

\section{The formation of onomatopoeia in Brazilian comics: orthographic and phonological issues}

\begin{abstract}
This research aims to investigate onomatopoeia from Brazilian comics, by observing the relation between phonology and spelling established in these words. For this work, 60 comics were observed from the magazines "Turma da Mônica" (Mônica, Magali, Cascão, Cebolinha, Chico Bento and Turma da Mônica) and 162 onomatopoeia were collected. After collecting these data, we observed the relation between spelling and phonology. We noticed in this study that writing onomatopoeias undergo a process of spelling styling - often in order to bring prosodic elements to the word, such as volume and duration. Another interesting fact is that the onomatopoeia may present sequences restricted to few uses in Portuguese, although allowed by the syllabic template of the language.
\end{abstract}

Keywords: onomatopoeia; orthography; phonology.

\section{Introdução}

O objetivo desta pesquisa é investigar onomatopeias a partir dos quadrinhos brasileiros, observando a relação entre fonologia e ortografia que se estabelece na escrita desses vocábulos, que Cagliari (1993, p. 616) chama de "escrita do barulho". A importância deste estudo reside no fato de que ainda são poucos os trabalhos da área de Linguística que se dedicam a observar, enquanto sistema, a linguagem verbal presente nos quadrinhos, pois, durante muito tempo, foram desconsiderados como objetos de estudos acadêmicos. 
De acordo com Vergueiro (2005, p. 17), na década de 1970, muitos estudiosos simplesmente não consideravam dignos de atenção os pesquisadores interessados por histórias em quadrinhos (ou HQs) e, "com isso, colocaram um ponto final no assunto, afirmando que as histórias em quadrinhos definitivamente não pertenciam ao meio acadêmico”. Além disso, segundo Ramos (2012), levar histórias em quadrinhos para a sala de aula era algo, até pouco tempo, inaceitável.

Entretanto, atualmente, além de despertarem interesses acadêmicos, os quadrinhos foram incluídos nos Parâmetros Curriculares Nacionais (PCN), sendo bemvindos em nossas salas de aula e marcando presença constante em provas de vestibulares e concursos. Todavia, podemos dizer que, ainda hoje, são poucos os estudos que realizam análises fonológicas, morfológicas, sintáticas ou lexicais do Português Brasileiro (doravante PB) a partir da linguagem dos quadrinhos.

Para Luyten (1985, p. 11-12), os quadrinhos nasceram do conjunto de duas artes diferentes - literatura e desenho ${ }^{1}$ - o que não os desmerece, “ao contrário, essa função, esse caráter misto que deu início a uma nova forma de manifestação cultural é o retrato fiel de nossa época, onde as fronteiras entre os meios artísticos se interligam”. Segundo a autora (LUYTEN, 1985, p. 7), os preconceitos com relação aos quadrinhos estão ficando cada vez menos frequentes, pois “a grande maioria das pessoas já está conscientizada da enorme importância que têm as histórias em quadrinhos. Tanto na área da educação como nas de lazer e até nos campos da propaganda comercial e política”. Ademais, lembra a estudiosa, essas histórias são excelente veículo de mensagens ideológicas e de crítica social, explícita ou implícita.

Embora o interesse em torno desse hipergênero ${ }^{2}$ tenha aumentado, ainda são poucos os trabalhos da área de Linguística que se dedicam a observar, enquanto sistema, a linguagem verbal presente nas HQs, tirinhas, charges e outros tipos de quadrinhos. Desse modo, podemos dizer que, ainda hoje, são poucos os estudos que realizam análises fonológicas, morfológicas, sintáticas ou lexicais do PB a partir da linguagem dos quadrinhos ${ }^{3}$.

\footnotetext{
${ }^{1}$ Para Ramos (2012, p. 17), dizer que os quadrinhos são uma forma de literatura é apenas uma forma de procurar rótulos socialmente aceitos ou academicamente prestigiados. De acordo com o pesquisador, quadrinhos são quadrinhos e, desse modo, "têm uma linguagem autônoma, que usa mecanismos próprios para representar os elementos narrativos”. Há pontos em comum com a literatura, mas também com o cinema, o teatro e muitas outras linguagens.

${ }^{2}$ Compartilhamos, neste trabalho, da linha teórica de Cagnin (1975), Mendonça (2002) e Ramos (2005, 2006, 2012), que veem os quadrinhos como um hipergênero (termo usado por Maingueneau em diversas obras, como Maingueneau, 2006), o que significa dizer que o termo “quadrinhos” é um rótulo que agrega diferentes gêneros, cada um com suas particularidades. Assim, "um hipergênero anteciparia informações textuais ao leitor e ao produtor e funcionaria como um guarda-chuva para diferentes gêneros, todos autônomos, mas com características afins” (RAMOS, 2009, p. 366). Ramos (2009, p. 362) explica que "podem ser abrigados dentro do hipergênero chamado quadrinhos os cartuns, as charges, as tiras cômicas, as tiras cômicas seriadas, as tiras seriadas e os vários modos de produção das histórias em quadrinhos”.

3 Ramos (2007, p. 1576) explica que há vários trabalhos sobre quadrinhos pertencentes à área de Comunicação que enfocam as características da linguagem desses gêneros enquanto veículos de comunicação de massa. $\mathrm{O}$ autor acrescenta que os estudos pertencentes à área da Linguística só ganharam força na segunda metade da década de 90 e fortaleceram-se definitivamente neste século. O pesquisador observou 11 anos (de 1995 a 2005) de publicações da Revista Estudos Linguísticos e notou que havia apenas dez artigos sobre quadrinhos. Com relação à temática desses estudos, Ramos (2007, p. 1575) notou "que as abordagens convergem para quatro campos temáticos: oralidade, gênero, educação e estratégias textuais, discursivas ou semióticas de formação de sentido”.
} 
Este artigo encontra-se estruturado em três seções. A primeira seção apresenta os referenciais teóricos que foram usados para compor este artigo; a segunda seção apresenta a metodologia para a coleta dos dados e, na última seção, é realizada a análise dos dados. Por fim, expomos algumas conclusões a que chegamos a partir da análise desses dados. Portanto, com essa pesquisa, esperamos colaborar com os estudos sobre a linguagem verbal presente nos quadrinhos brasileiros.

\section{Fundamentação teórica}

Dentre os estudos que observam a linguagem dos quadrinhos, há alguns trabalhos (como EGUTI, 2001; PASSARELLI, 2004 e RAMOS, 2005) que ressaltam os aspectos da oralidade ali representada. Segundo essas pesquisas, sobretudo Eguti (2001), podemos notar que os diversos tipos de quadrinhos são um terreno fértil para a representação da língua falada, bem como dos demais elementos que a constituem, como gestos, voz e outros. Ramos (2006, p. 1580) acredita que os quadrinhos simulam as várias características da língua falada, de modo que os balões representam os turnos conversacionais e "o formato das letras e o contorno dos balões indicariam tom de voz mais elevado, mais baixo, a emoção sentida no momento da fala do personagem”.

Levando em consideração o estudo de Eguti (2001), no fim dos anos 90, a "Turma da Mônica” apresentava uma fala bastante fiel à coloquial, assim, acreditamos que seja possível observar nos quadrinhos nacionais algumas tendências atuais do PB, pois, ao simularem a língua oral, os quadrinhos apresentam uma linguagem rica em expressividade e inovação linguística, e tornam-se, assim, um excelente material de estudos para analisar fenômenos linguísticos típicos da fala oral, como adaptações fonológicas de estrangeirismos, gírias, processos morfofonológicos que ocorrem na formação de palavras, processos fonológicos típicos da língua oral (como supressão e fusão de sons), entre outros fatos que podem transparecer a partir da ortografia flexível e informal dos quadrinhos atuais.

Como nosso estudo se propõe a observar onomatopeias, fez-se necessário, primeiramente, rever algumas definições clássicas para esse termo. As onomatopeias são classificadas por Alves (1990) como sendo um tipo de neologismo fonológico, o que significa, do ponto de vista da autora, que esse tipo de neologia supõe a "criação de um item léxico cujo significante seja totalmente inédito, isto é, tenha sido criado sem base em nenhuma palavra já existente” (ALVES, 1990, p. 11). A autora acrescenta que esse tipo de neologismo é raro em todas as línguas e está calcado em significantes inéditos.

Entretanto, ela reforça que "a formação de palavras onomatopaicas não é totalmente arbitrária, já que ela se baseia numa relação, ainda que imprecisa, entre a unidade léxica criada e certos ruídos ou gritos” (ALVES, 1990, p. 12). A autora explica que esse recurso procura reproduzir um som, o que "impossibilita que seu significante seja imotivado" (ALVES, 1990, p. 12). Para ela, esse recurso é bastante produtivo em certas linguagens, como, por exemplo, em histórias em quadrinhos. Embora as reflexões da autora sejam válidas, essa explicação, de que uma palavra onomatopaica é criada a partir de “ruídos ou gritos”, não nos parece ser o caso mais comum nas línguas.

Sandmann (1997, p. 22), ao comentar os artifícios de ampliação do léxico do PB, afirma que a língua faz uso de três recursos para ampliar seu vocabulário, sendo que dois deles são marginais. De acordo com o autor, os recursos secundários são os empréstimos 
de outras línguas e a "criação do nada” - que consiste na formação de palavras através de fonemas ou sílabas já existentes na língua (como dizer "tututu” - onomatopeia para o som de término de uma ligação telefônica). Esse processo usado pelo autor nos parece pouco adequado, afinal esse tipo de formação de palavras envolve a mimetização de sons do mundo, apoiando-se nas possibilidades fonológicas de uma língua. Assim, essas criações não surgem “do nada” e, sim, das opções fonológicas do idioma. Desse modo, a definição de Alves (1990), apresentada anteriormente, mesmo não sendo a ideal, mostra-se mais adequada do que a definição de Sandmann.

Segundo Luyten (1985, p. 13), as onomatopeias, assim como os balões, completam os quadrinhos e lhes dão efeito de grande beleza sonora. A autora explica que

[...] nos quadrinhos japoneses, por exemplo, as onomatopeias têm uma função muito mais plástica do que visual e sonora. Isso porque a escrita japonesa é formada por caracteres e as onomatopeias inseridas nos quadrinhos dão um incrível movimento, equilíbrio, e força ao som que estão exprimindo.

Para a estudiosa, a expressão dos ruídos onomatopaicos se relaciona também com a língua inglesa (já que o surgimento das tiras diárias na primeira década do século passado coincide com a explosão da imprensa norte-americana), o que explicaria, para ela, o fato de muitas onomatopeias, que já são dotadas de significado em inglês, quando transportadas para outras línguas, ficarem apenas com a função de signos visuais, isto é, passam a ser uma espécie de convenção artística na linguagem das HQs. A autora diz que, enquanto tradutora de quadrinhos, sempre procurou respeitar a forma original das onomatopeias, mas, atualmente os desenhistas brasileiros, na criação de suas histórias, "começaram a buscar e adotar uma grafia onomatopaica mais pertinente à nossa língua, trazendo, consequentemente, uma assimilação eficaz e um contato mais direto com o leitor” (LUYTEN, 1985, p. 15).

Cagliari (1993, p. 618-619) enxerga nas expressões onomatopaicas um retrato de regras e tendências da língua:

Por que falamos 'blá-blá-blá, rarará' com três repetições de um monossílabo ou 'lerolero, lenga-lenga’ com duas repetições de dissílabo? Certamente está aí uma tendência da língua. O mesmo se observa colocando acento na fala dessas expressões. As formas variantes: 'tchigum e tigum, tóim, tóin e tóing' sem dúvida revelam formas alofônicas típicas da fonologia da língua. A forma 'tigum', hoje, está sendo mais usada representando mesmo a pronúncia palatalizada que está se espalhando pelo país. A escrita de formas como 'tac, slap, crak, vapt', e não 'taque, eslape, craque, vápite' não é só questão de (orto)grafia. Será que não revelam também tendências rítmicas e fonológicas da língua? A evidência da duração da formação da tonicidade também é claramente representada na escrita do barulho através da repetição de letras. Enfim, embora restrito a um uso especial de linguagem, a um certo estilo, a escrita do barulho pode nos ajudar a entender melhor o próprio sistema de escrita e de fala.

De acordo com Câmara Jr. (1978, p. 41), a maneira mais simples de se obter um efeito estilístico com o emprego de palavra sonicamente adequada é recorrer às onomatopeias que, para ele, "são elementos vocabulares ainda à margem do sistema intelectivo, propriamente dito, da linguagem”. O linguista explica que as onomatopeias exteriorizam, de certa forma, “a comunhão psíquica com o mundo das coisas” e estão no polo oposto das palavras tradicionais que, em princípio, tem um simbolismo arbitrário. O 
autor comenta que a motivação sonora com base em onomatopeias aparece frequentemente na linguagem infantil e na poesia, mas não menciona as HQs que, como se sabe, muito se utilizam de onomatopeias para garantir maior expressividade às narrativas.

O autor lembra que é natural que "a estilística fônica aproveite primacialmente os traços fonéticos que não estão sistematicamente utilizados nas oposições e nas correlações dos fonemas e dos grupos fonêmicos" (CÂMARA JR., 1978, p. 29). Dois desses traços estilísticos, explica Câmara Jr., são o acento vocabular de altura (ou tom) e a quantidade vocálica. Entretanto, como veremos nas análises de dados, também podemos ver estilizações com relação ao molde silábico da língua, por exemplo, em relação às consoantes que podem ocupar determinadas posições nas sílabas.

Em virtude da extensão deste artigo, faremos apenas um breve resumo sobre as vogais, consoantes e moldes silábicos do PB.

Segundo Massini-Cagliari e Cagliari (2006, p. 129), as vogais que podem ser encontradas na posição tônica em PB são: [i], como em abacaxi ; [e], como em beleza; [ع], como em belo; [a], como em batata; [0], como em bola; [u], urubu. Além dessas, os autores mencionam a vogal [e], que é bastante frequente e pode ocorrer nasalizada ou não (como em cama e banana)

De acordo com Massini-Cagliari e Cagliari (2006, p. 126), as consoantes são sons que "apresentam contatos ou constrições no aparelho fonador facilmente analisáveis, sobretudo pela repetição da articulação em comparação com gestos semelhantes e próximos”. Por isso, explicam os autores, as consoantes são geralmente classificadas em termos de modo e lugar de articulação e, também, quanto à presença ou ausência de vibração das cordas vocais, além das características do processo aerodinâmico envolvido. Câmara Jr. (2004 [1970], p. 48) elenca 19 consoantes para o PB de acordo com o quadro 1:

Quadro 1. Consoantes do PB (adaptado de Câmara Jr., 2004 [1970], p. 48)

\begin{tabular}{|c|c|c|c|c|c|}
\hline$/ \mathrm{p} /$ & roupa & /b/ & rouba & & \\
\hline$/ \mathrm{f} /$ & mofo & $/ \mathrm{v} /$ & movo & & \\
\hline$/ \mathrm{k} /$ & roca & $/ g /$ & roga & & \\
\hline$/ \mathrm{s} /$ & aço & $\mid \mathrm{z} /$ & azo & & \\
\hline$/ \mathrm{d} /$ & acho & $\mid 3 /$ & ajo & & \\
\hline$/ \mathrm{m} /$ & amo & $/ \mathrm{n} /$ & ano & $/ \mathrm{n} /$ & anho \\
\hline$/ \mathrm{l} /$ & mala & $|x|$ & malha & & \\
\hline$/ \mathrm{t} /$ & rota & $/ \mathrm{d} /$ & roda & & \\
\hline$/ \mathrm{R} /$ & erra & $/ \mathrm{f} /$ & era & & \\
\hline
\end{tabular}

Collischonn (2005 [1996], p. 117) explica que não há consenso entre os estudiosos em relação ao molde silábico do $\mathrm{PB}$, que determina o número máximo e mínimo de elementos permitidos em uma sílaba desta língua. A autora define os seguintes padrões silábicos para o $\mathrm{PB}$ : 
Quadro 2. Padrões silábicos do PB (COLLISCHONN, 2005 [1996], p. 117)

\begin{tabular}{|l|l|}
\hline $\mathrm{V}$ & é \\
\hline VC & ar \\
\hline VCC & instante \\
\hline CV & cá \\
\hline CVC & lar \\
\hline CVCC & monstro \\
\hline CCV & tri \\
\hline CCVC & três \\
\hline CCVCC & transporte \\
\hline VV & aula \\
\hline CVV & lei \\
\hline CCVV & grau \\
\hline CCVVC & claustro \\
\hline
\end{tabular}

Ainda em relação ao português, Cagliari (2007, p. 116) propõe os moldes silábicos apresentados no quadro $3^{4}$ :

Quadro 3. Sílabas do português (CAGLIARI, 2007, p. 116)

\begin{tabular}{|c|c|c|c|}
\hline $\begin{array}{l}\text { Padrão } \\
\text { Silábico }\end{array}$ & Exemplo & $\begin{array}{l}\text { Forma } \\
\text { ortográfica }\end{array}$ & \\
\hline \multirow[t]{2}{*}{$\mathrm{V}$} & {$[\varepsilon]$} & É & $\mathrm{M}$ \\
\hline & {$[\mathrm{e} \oplus]$} & $\mathrm{Eu}$ & $\mathrm{D}$ \\
\hline $\mathrm{CV}$ & {$[\mathrm{p} \varepsilon]$} & Pé & $\mathrm{M}$ \\
\hline \multirow[t]{2}{*}{$\mathrm{CV}$} & [teø] & Teu & $\mathrm{D}$ \\
\hline & [kळa@] & Qual & $\mathrm{T}$ \\
\hline \multirow[t]{2}{*}{$\mathrm{CCV}$} & [kru] & Cru & $\mathrm{M}$ \\
\hline & [kreø] & Creu & $\mathrm{D}$ \\
\hline \multirow[t]{2}{*}{$\mathrm{VC}$} & {$[\varepsilon s]$} & És & $\mathrm{M}$ \\
\hline & [ets] & Eis & $\mathrm{D}$ \\
\hline \multirow[t]{2}{*}{ VCC } & [xú I) s] & Ruins & $\mathrm{M}$ \\
\hline & {$[$ léo)ı)s] } & Leões & $\mathrm{D}$ \\
\hline \multirow[t]{3}{*}{ CVCC } & [pes] & Pés & $\mathrm{M}$ \\
\hline & [teøs] & Teus & $\mathrm{D}$ \\
\hline & [køais] & Quais & $\mathrm{T}$ \\
\hline \multirow[t]{3}{*}{ CVCC } & [perspekttiva] & Perspectiva & $\mathrm{M}$ \\
\hline & $\left.[\mathrm{me}) \mathrm{l}) \mathrm{s}_{\mathrm{s}}\right]$ & Mães & $\mathrm{D}$ \\
\hline & [ságøo)ı)/s] & Saguões & $\mathrm{T}$ \\
\hline \multirow[t]{2}{*}{ CCVC } & [plastıkø] & Plástico & $\mathrm{M}$ \\
\hline & [u)mbrais] & Umbrais & $\mathrm{D}$ \\
\hline \multirow[t]{2}{*}{ CCVCC } & [tre) $)$ s] & Trens & $\mathrm{M}$ \\
\hline & $[\mathrm{k} \square \mathrm{bro}) \mathrm{t}) \mathrm{s}]$ & Cobrões & $\mathrm{D}$ \\
\hline
\end{tabular}

Importante ressaltar que, para Collischonn (2005, p. 120), em língua portuguesa, determinadas sequências de segmentos não são permitidas no onset complexo. Nesta posição, as sequências permitidas são plosiva + líquida; entretanto, os grupos /dl/, /tl/ e /vl/, apesar de permitidos pelo molde, são restritos a nomes próprios de origem estrangeira, como Vladimir. A autora também considera que o grupo /tl/ ocorre na palavra atlas e seus derivados. No entanto, podemos encontrar o grupo /dl/ em siglas, como em DLA (Departamento de Linguística Aplicada). Além disso, em posição inicial de palavra,

\footnotetext{
${ }^{4}$ No quadro 3, M significa monotongo, D significa ditongo e T significa tritongo.
} 
não ocorre $/ \mathrm{n} /$ e $/ \lambda /$, de modo que só encontramos estes segmentos nesta posição em palavras emprestadas de outras línguas, como, por exemplo, lhama e nhoque.

\section{Procedimentos metodológicos}

Com relação à metodologia, para este trabalho, foram observadas, a partir das revistas “Turma da Mônica” (Mônica 11, Cebolinha 11, Magali 11, Cascão 11, Chico Bento 11 e Turma da Mônica 11), 60 histórias em quadrinhos e coletadas 162 onomatopeias. Como são muitas palavras, no Quadro 4, abaixo, podemos ver apenas uma amostra, com alguns exemplos dos vocábulos coletados, e a maneira como se dá a organização das onomatopeias em nosso estudo.

Quadro 4. Amostra de vocábulos coletados

\begin{tabular}{|c|c|c|}
\hline \multicolumn{3}{|c|}{ ONOMATOPEIAS } \\
\hline $\begin{array}{l}\text { Itens e variantes } \\
\text { ortográficas }\end{array}$ & Ocorrências/publicação & Referência; contexto \\
\hline Arf & 15/ CHICO BENTO 11, p. 48; 49; 50; 59; 62 & $\begin{array}{l}\text { Som de respiração por esforço } \\
\text { físico }\end{array}$ \\
\hline Blllr & 1/ CEBOLINHA 11, p. 57 & $\begin{array}{l}\text { Som de personagens tremendo de } \\
\text { frio }\end{array}$ \\
\hline Bmfff (bmmfff) & 2/ CEBOLINHA 11, p. 45 & Irritação \\
\hline Buuuuu & 1/ CEBOLINHA 11, p. 62 & $\begin{array}{l}\text { Som de personagem tremendo de } \\
\text { frio }\end{array}$ \\
\hline Bzap & 1/ TURMA DA MÔNICA 11, p. 15 & $\begin{array}{l}\begin{array}{l}\text { Som de descarga elétrica na } \\
\text { tomada }\end{array} \\
\end{array}$ \\
\hline Cablam & 1/ CEBOLINHA 11, p. 15 & $\begin{array}{l}\text { Som de caixa sendo jogada no } \\
\text { chão }\end{array}$ \\
\hline Cabrum & 2/ CASCÃO 11, p. 25, 66 & Som de Trovão \\
\hline Caham & $\begin{array}{l}\text { 1/ CEBOLINHA 11, p. } 48 \text { - 1/MAGALI 11, } \\
\text { p. } 16-\text { 1/ MÔNICA 11, p. } 62\end{array}$ & Som feito para chamar a atenção \\
\hline Capof & 1/ MÔNICA 11, p. 62 & Som de agressão física \\
\hline Catablam & 1/ TURMA DA MÔNICA 11, p. 6 & Som de queda \\
\hline Chomp & $\begin{array}{l}\text { 2/ CHICO BENTO 11, p. } 16 \text { - 16/MAGALI } \\
\text { 11, p. 22; 29; 54; } 55 \text { - 2/ TURMA DA } \\
\text { MÔNICA 11, p. } 18\end{array}$ & $\begin{array}{l}\text { Som de personagem mastigando/ } \\
\text { comendo }\end{array}$ \\
\hline Cococoricóóóó!! & 1/ CHICO BENTO 11, p. 38 & Som de galo cantando \\
\hline Crac & 1/ CASCÃO 11, p. 60 & Som de carrinho quebrando \\
\hline Crash & 1/ CEBOLINHA 11, p. 54 & Som de espelho quebrando \\
\hline Crec (creec) & $\begin{array}{l}\text { 1/ CASCÃO 11, p. } 60 \text { - 1/ CHICO BENTO } \\
\text { 11, p. } 51\end{array}$ & Som de carrinho quebrando \\
\hline Cri & 3/ MÔNICA 11, p. 55 & Som de grilo \\
\hline Crinch & $\begin{array}{l}\text { 1/ CHICO BENTO 11, p. } 61 \text { - 1/ MAGALI } \\
\text { 11, p. } 38 \text { - 1/ TURMA DA MÔNICA 11, p. } \\
19\end{array}$ & $\begin{array}{l}\text { Som de carro estacionando; som } \\
\text { de parada abrupta de personagem; } \\
\text { som de javali }\end{array}$ \\
\hline Cruim & 2/ CHICO BENTO 11, p. 60 & Som de javali \\
\hline Ding dong & $\begin{array}{l}\text { 3/ MÔNICA 11, p. 3; .5; } 7 \text { - 2/ TURMA DA } \\
\text { MÔNICA 11, p.11 - }\end{array}$ & Som de campainha \\
\hline Dlim & 3/ CEBOLINHA 11, p. 60 & Som do trenó do papai Noel \\
\hline Glin & 3/ MAGALI 11, p. 57 & Som de celular recebendo e-mail \\
\hline Glu & 2/ MÔNICA 11, p. 27 & Som de ingestão de bebida \\
\hline $\begin{array}{c}\text { Itens e variantes } \\
\text { ortográficas }\end{array}$ & Ocorrências/publicação & Referência; contexto \\
\hline Glup & $\begin{array}{l}\text { 2/ CASCÃO 11, p. 61; } 63 \text { - 1/ CHICO } \\
\text { BENTO 11, p. 3-3/ MÔNICA 11, p. 24; 62; }\end{array}$ & Som de engasgo \\
\hline
\end{tabular}




\begin{tabular}{|l|l|l|}
\hline & $\begin{array}{l}64-4 / \text { TURMA DA MÔNICA 11, p. 13; 16; } \\
21 ; 48\end{array}$ & \\
\hline Nham & 1/ TURMA DA MÔNICA 11, p. 22 & Som de personagem salivando \\
\hline Pinc & 1/ MAGALI 11, p. 10 & Som de cutucão \\
\hline
\end{tabular}

Como se pode notar, o quadro está organizado em três colunas, sendo que, na primeira coluna, colocamos as onomatopeias e suas variantes ortográficas, na segunda coluna organizamos o número de ocorrências por publicação, apontando o número das páginas em que estão e, por fim, na terceira estão apontadas as referências de sentido e de contexto.

Após a coleta das onomatopeias, passamos a analisar a relação entre fonologia e ortografia.

\section{Análise dos dados}

Em nossa análise, quando observamos os processos de formação dessas palavras e sua ortografia, a principal questão que surgiu foi: como representar um som que, na maioria das vezes, não tem ortografia definida (dicionarizada)? Acreditamos que, a partir da observação de diversas onomatopeias presentes nos quadrinhos, é possível observar as tendências de escrita desses vocábulos, que seguem, muitas vezes, uma ortografia estilizada, isto é, uma ortografia que difere da grafia oficial do PB (PRADO, 2014). A estilização ortográfica não é exclusiva de onomatopeias. Pode aparecer também em interjeições, nomes próprios, como antropônimos (MASSINI-CAGLIARI, 2010, 2011a,b, 2013; SOUZA, 2011; MACEDO, 2015), como Mariah, Sarah e Kharla, e nomes comerciais (PRADO, 2014), como Autocenter Skinão e Ki-Bom, além de aparecer também em hipocorísticos (MACEDO, 2015), como Titiny, hipocorístico de Valentine, e na linguagem da internet.

Cagliari (1993, p. 616), que também analisou as onomatopeias de diversos quadrinhos, acredita que a escrita dessas palavras "apresenta questões interessantes não só graficamente, como também para a ortografia e até para a gramática de uma língua”. Pudemos observar, neste estudo, que a escrita das onomatopeias passa por um processo de estilização da ortografia - muitas vezes com o intuito de trazer elementos prosódicos para o vocábulo, como, por exemplo, volume e duração ${ }^{5}$, como nas onomatopeias que representam gritos, como "aaaahhhhh" (Figura 1), em que a repetição de letras pode indicar a duração desses gritos; ou como em “fuééé!” (Figura 2) em que, além da repetição de letras, se vê uma fonte mais grossa e colorida, o que parece indicar o alto volume do som.

\footnotetext{
${ }^{5}$ Além da grafia das palavras, o balão de fala, por ser o elemento que mais caracteriza e dá dinamicidade à leitura dos quadrinhos, também pode carregar elementos prosódicos e expressar emoções das personagens: "na sua forma bem-comportada, indica a fala coloquial de seus personagens. No entanto, quando estes mudam de humor, expressando emoções diversas (surpresa, ódio, alegria, medo), os balões acompanham tipologicamente, participando também da imagem. As formas são muitas e bastante variadas. Partindo-se do balão-fala, podemos encontrar o balão-pensamento, balão-berro, balão-cochilo, balão-trêmulo (medo), balão-transmissão (para transmitir sons de aparelhos elétricos ou eletrônicos), balão-desprezo, balãouníssono (mostrando a fala única de diversos personagens), balão mudo e dezenas de informações diversas. Esses tipos e formas vão depender sempre da situação que se quer criar, ocasionando, assim, ótimos efeitos visuais e comunicativos” (LUYTEN, 1985, p. 12-13).
} 


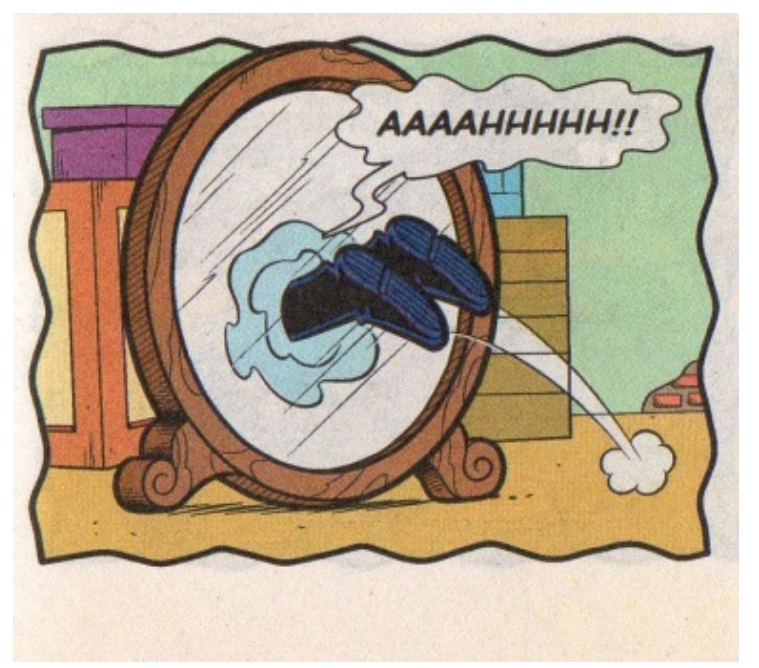

Figura 1. Cebolinha (nº 11, p. 40)

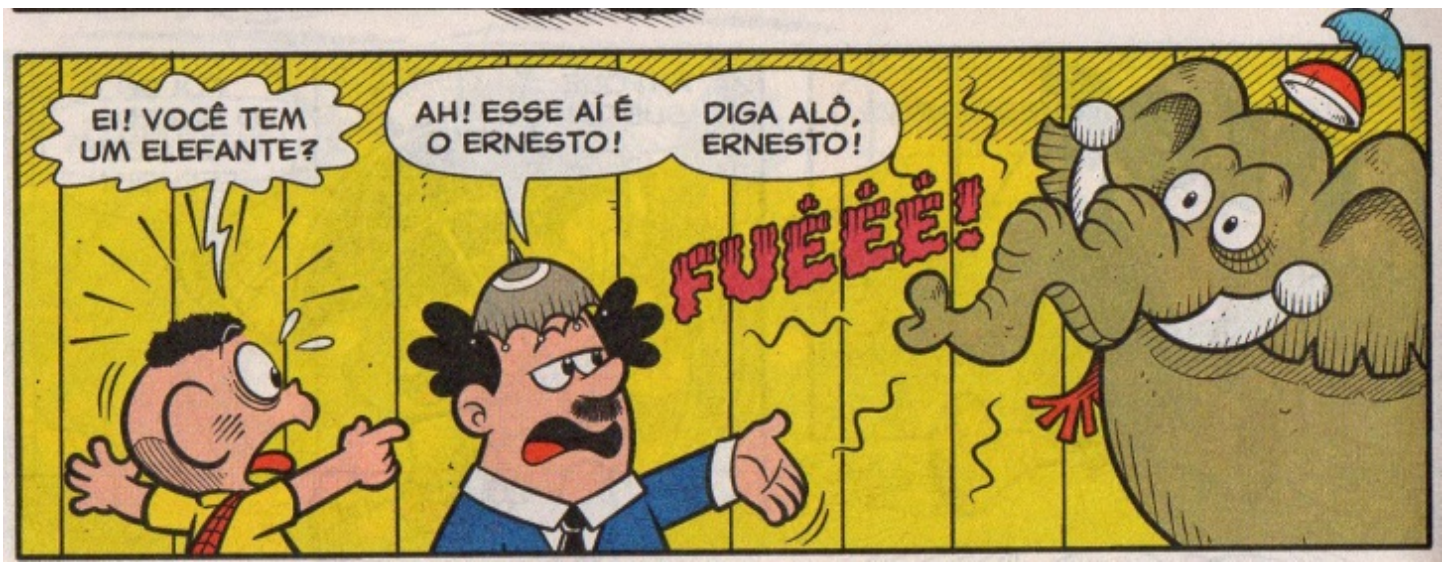

Figura 2. Cascão (nº 11, p. 14)

Outro fato interessante é que as onomatopeias podem apresentar, inclusive, sequências que, apesar de permitidas pelo molde silábico da língua portuguesa, conforme descrito na seção de fundamentação teórica (COLLISCHONN, 2005, p. 120), acabam restritas a poucos usos, como a sequência de onset /vl/, /tl/ e /dl/. Esses grupos, com uso restrito no $\mathrm{PB}$, podem ser encontrados nas onomatopeias, como podemos observar nos vocábulos tlim ${ }^{6}$, vlam e dlim, nas Figuras 3, 4 e 5, respectivamente.

\footnotetext{
${ }^{6}$ Como se pode observar, o quadrinho da Figura 3, que traz a onomatopeia tlim, não pertence às revistas observadas para este trabalho, mas a outra publicação, por isso não entrou na contagem de onomatopeias deste estudo.
} 


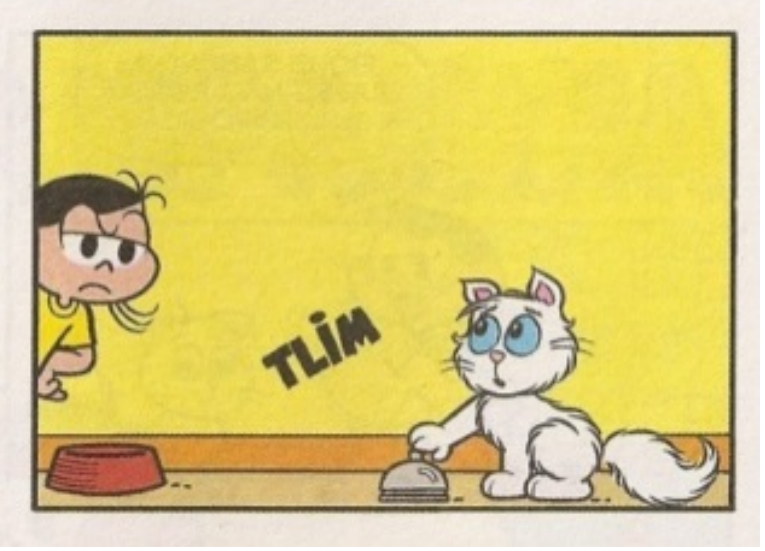

Figura 3. Magali (n 99 , p. 30)

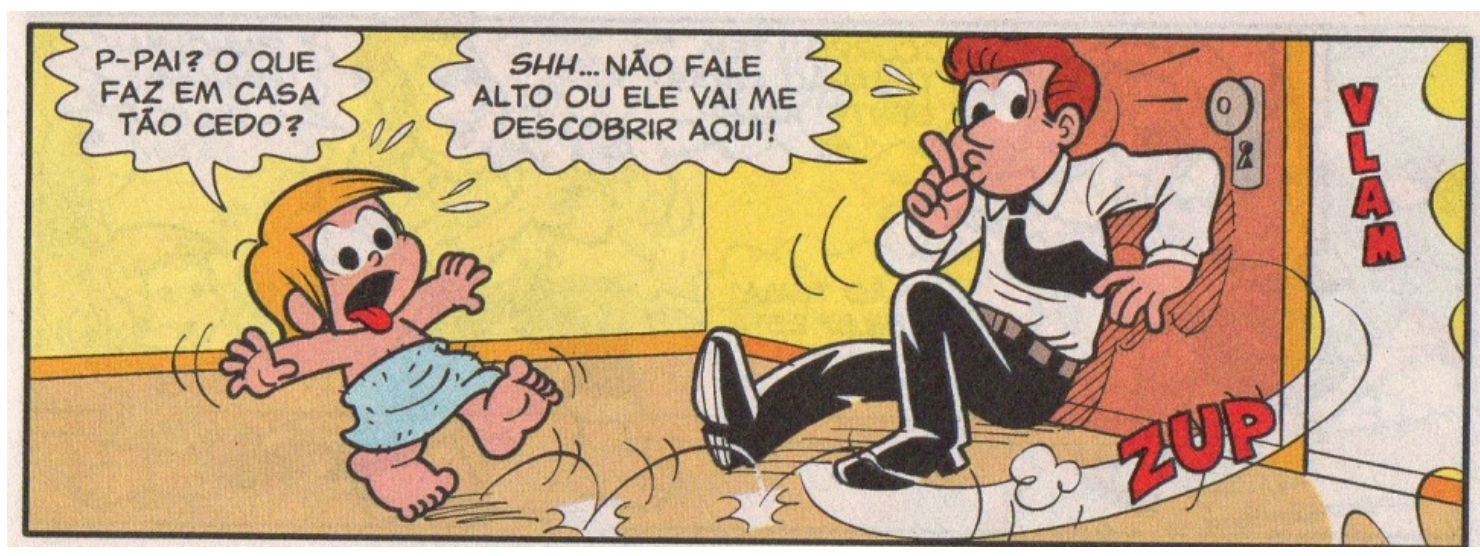

Figura 4. Turma da Mônica (nº 11, p. 11)

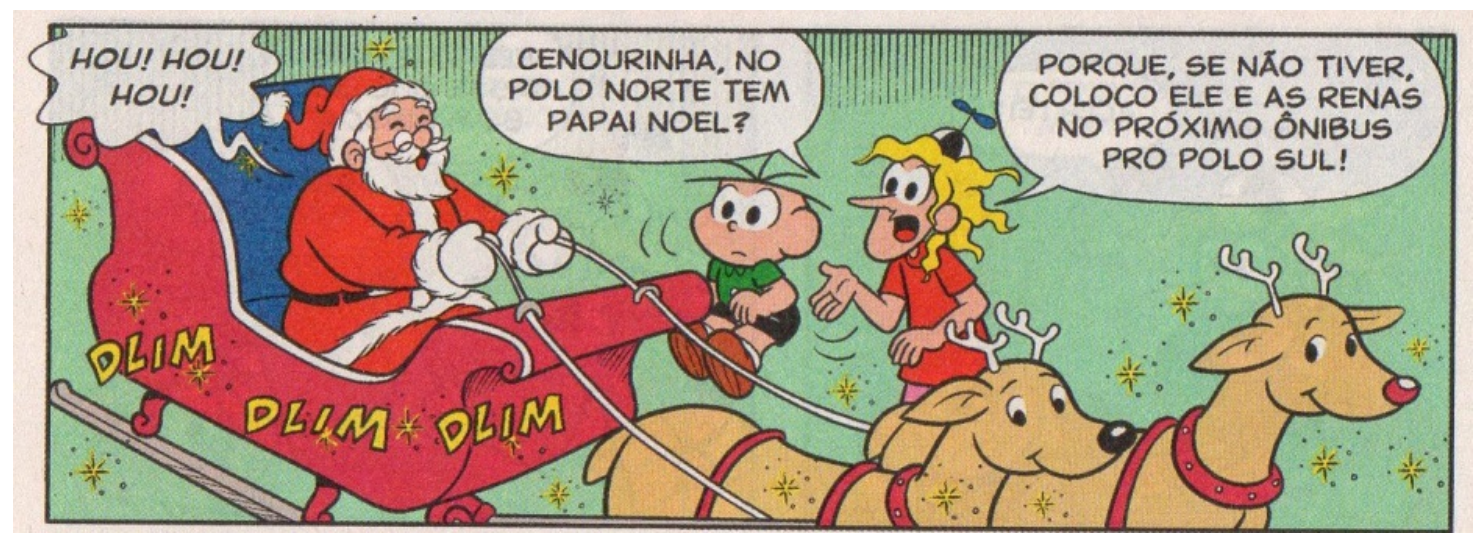

Figura 5. Cebolinha (n ${ }^{0}$ 11, p. 40)

Além disso, em posição inicial de palavra, em PB não ocorre $/ \mathfrak{n} / \mathrm{e} / \lambda /$, de modo que só encontramos estes segmentos nesta posição em palavras emprestadas de outras línguas, como, por exemplo, lhama e nhoque. Entretanto, foi possível encontrar /n/ no início de uma palavra onomatopaica, como podemos ver na onomatopeia que representa o som de uma pessoa salivando, nham (Figura 6). 


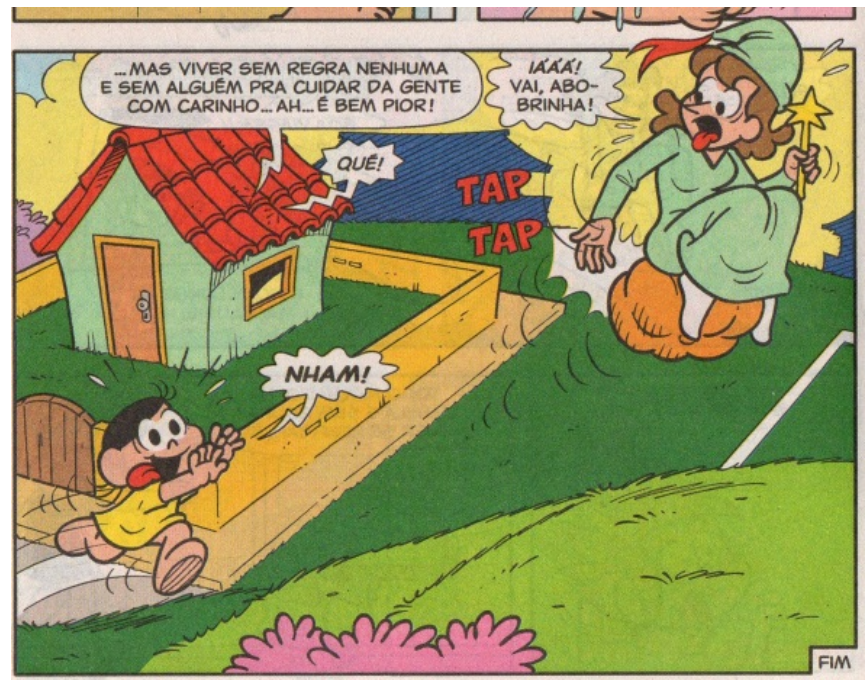

Figura 6. Turma da Mônica $\left(n^{\circ} 11\right.$, p. 22)

Também é possível notar onomatopeias ortograficamente formadas sem vogais, como Bmfff (Figura 7), que, nesse caso, funciona mais como interjeição e indica irritação da personagem. Esse tipo de vocábulo desafia o padrão silábico e ortográfico do PB, que não permite sílabas sem vogais e, talvez, possa ser interpretado apenas como sendo um ruído emitido pela pessoa, indicativo de seu humor, e não exatamente como uma palavra da língua.

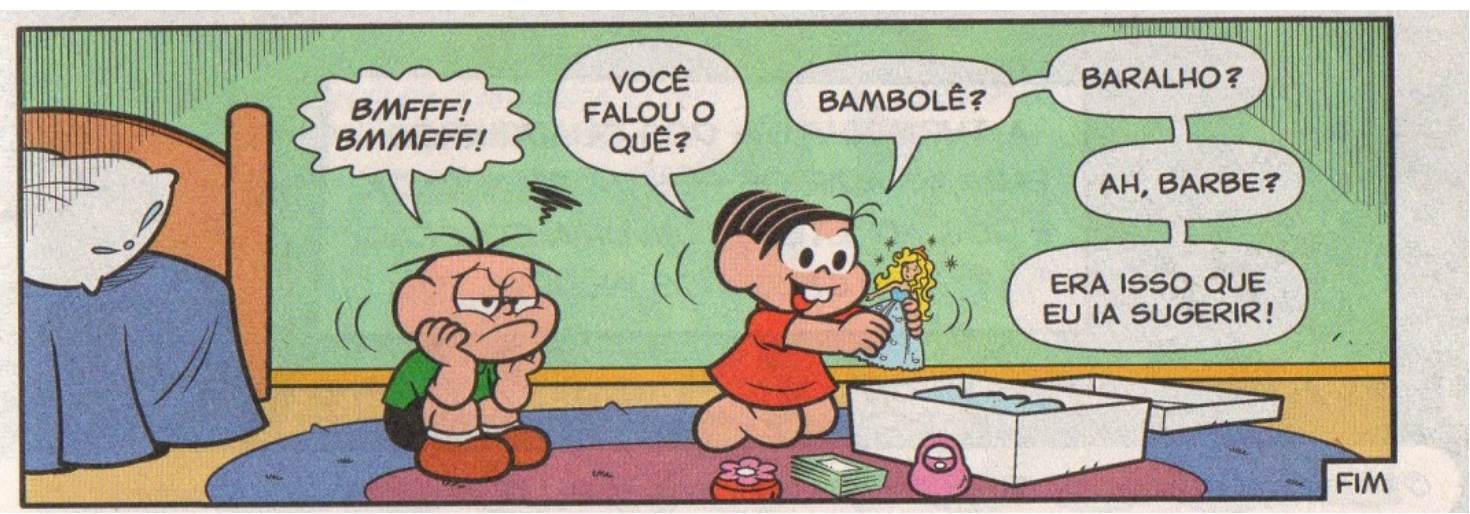

Figura 7. Cebolinha (no 11, p. 45)

Como exposto, conseguimos coletar 162 onomatopeias, de modo que foi possível perceber uma grande riqueza lexical nos quadrinhos usados para a composição do nosso corpus.

\section{Considerações finais}

Os quadrinhos são um terreno fértil para pesquisas linguísticas. Atualmente, observa-se que as publicações de quadrinhos, por destinarem-se a um público consumidor muito amplo, representam um índice expressivo da cultura de massa e merecem atenção. Suas histórias e personagens estão sempre acompanhando a evolução cultural, tecnológica e linguística, de modo que a maneira de escrever os quadrinhos também sente necessidade de acompanhar essa evolução. 
Diante disso, acreditamos que a ortografia de onomatopeias (e de interjeições e de casos de escrita fonética) dos quadrinhos também pode receber influência da linguagem da internet, em que é permitida uma escrita mais livre, cheia de abreviações e estilizações ortográficas. Por serem os quadrinhos uma fonte escrita acessada por crianças e jovens em idade escolar, estudar os processos de estilização da sua grafia pode render reflexões importantes também sobre o papel desses materiais em sala de aula, até mesmo no estudo das normas ortográficas oficiais do português no Brasil.

A ortografia da Língua Portuguesa é regida por regras (bases) e pelo VOLP (Vocabulário Ortográfico da Língua Portuguesa - versão da Academia Brasileira de Letras). Essas normas orientam como devem ser escritas as palavras, porém, no caso das HQs, a simples representação de sons, ruídos e sentimentos, seguindo as normas ortográficas, pode tirar o impacto que outras formas de se escrever, mais agressivas visualmente, poderiam trazer, tornando a escrita mais adequada aos propósitos da mensagem das HQs. Os cartunistas têm consciência dessa realidade.

Durante o levantamento bibliográfico para a escrita deste trabalho, observamos que a presença das onomatopeias em HQs não passa despercebida pelos estudiosos, no entanto, com exceção de Cagliari (1993), nenhum dos pesquisadores consultados até o momento observou a escrita dessas palavras do ponto de vista fonético/fonológico e ortográfico. Desse modo, faz-se necessário um estudo mais aprofundado para melhor caracterizar essas palavras a partir deste viés. Assim, com essa investigação, esperamos colaborar para a compreensão da relação entre ortografia e fonologia nas onomatopeias dos quadrinhos nacionais.

\section{REFERÊNCIAS}

ALVES, I. M. Neologismo: criação lexical. São Paulo: Ática, 1990.

CAGLIARI, L. C. A escrita do barulho. In: Estudos Linguisticos - Anais de seminários do GEL, São Paulo: Instituição Moura Lacerda, v. 22, p. 615-622, 1993.

Elementos de fonética do português brasileiro. São Paulo: Paulistana, 2007.

CAGNIN, A. L. Os quadrinhos. São Paulo: Ática, 1975.

CÂMARA JR., J. M. Estrutura da Língua Portuguesa. 36. ed. Petrópolis: Vozes, 2004 [1970].

CÂMARA JR., J. M. Contribuição à estilística portuguesa. Rio de Janeiro: Ao Livro Técnico, 1978.

CASCÃO. São Paulo: Panini Comics, n. 11, março 2016.

CEBOLINHA. São Paulo: Panini Comics, n. 11, março 2016.

CHICO BENTO. São Paulo: Panini Comics, n. 11, março 2016.

COLLISCHONN, G. A sílaba em português. In: BISOL, L. (Org.). Introdução a estudos de fonologia do português brasileiro. 4. ed. Porto Alegre: EDIPURCS, 2005 [1996]. p. 101-133.

EGUTI, C. A. A representatividade da oralidade nas histórias em quadrinhos. 2001. 198 f. Dissertação (Mestrado em Filologia e Língua Portuguesa) - Faculdade de Filosofia e Língua Portuguesa, Universidade de São Paulo, São Paulo, 2001. 
LUYTEN, S. M. B. O que é história em quadrinhos. São Paulo: Editora Brasiliense, 1985.

MACEDO, N. Z. Análise fonológica de nomes próprios de origem estrangeira e novas criações em Português Brasileiro. 2015. 171 f. Dissertação (Mestrado em Linguística e Língua Portuguesa) -Faculdade de Ciências e Letras, Universidade Estadual Paulista, Araraquara, 2015.

MAGALI. São Paulo: Panini Comics, n. 11, março 2016.

MAGALI. São Paulo: Panini Comics, n. 99, março 2015.

MAINGUENEAU, D. Discurso literário. Tradução de Adail Sobral. São Paulo: Contexto: 2006.

MASSINI-CAGLIARI, G.; CAGLIARI, L. C. Fonética. In: MUSSALIN, F.; BENTES, A. C. (Org.). Introdução à Linguística: Domínios e Fronteiras. v. 1. São Paulo: Cortez, 2006. p. 105-146.

Discutindo questões de identidade a partir da (não) adaptação fonológica de nomes próprios de origem estrangeira no Brasil. In: NEVES, M. H. de M. As interfaces da gramática. Araraquara: FCL-UNESP Laboratório Editorial; São Paulo: Cultura Acadêmica, 2010. (Série Trilhas Linguísticas 18). p. 73-90.

Loans and foreign first names as clues to Phonological Identity in Brazilian Portuguese. In: HORNSBY, D. (Org.). Interfaces in language 2. v. 1. Newcastle upon Tyne: Cambridge Scholars, 2011a. p. 53-67.

Adaptação fonológica de nomes próprios de origem estrangeira: comparação entre Português Arcaico e Português Brasileiro. Estudos Linguísticos, São Paulo, 40 (2), p. 795-807, mai.-ago. 2011b.

MENDONÇA, M. R. de S. Um gênero quadro a quadro: a história em quadrinhos. In: DIONISIO, A. P.; MACHADO, A. R.; BEZERRA, M. A. (Org.). Gêneros textuais \& ensino. Rio de Janeiro: Lucerna, 2002. p. 194-207.

MÔNICA. São Paulo: Panini Comics, n. 11, março 2016.

NEVES, M. H. de M. A gramática: conhecimento e ensino. In: Que gramática estudar na escola? Norma e uso na Língua Portuguesa. São Paulo: Contexto, 2003. p. 128-152.

PASSARELLI, L. G. Os quadrinhos na educação lingüística: história, teoria e prática. In: BASTOS, N. B. (Org.). Língua Portuguesa em calidoscópio. São Paulo: EDUC, 2004. p. 47-59.

PRADO, N. C. A influência da língua inglesa na formação de nomes comerciais: questões de identidade linguística e cultural. 2014. 343 f. Tese (Doutorado em Linguística e Língua Portuguesa)-Faculdade de Ciências e Letras, Universidade Estadual Paulista, Araraquara, 2014.

RAMOS, P. Piadas e tiras em quadrinhos: a oralidade presente nos textos de humor. Estudos Linguísticos, p. 1158-1163, 2005.

Histórias em quadrinhos: um novo objeto de estudos. Estudos Linguísticos, p. 1574-1583, 2006.

A leitura dos quadrinhos. São Paulo: Contexto, 2012.

SANDMANN, A. J. Morfologia Lexical. São Paulo: Contexto, 1997. 
SOUZA, S. M. L. S. de. Antropônimos de origem inglesa: adaptações ortográficas e fonético-fonológicas realizadas por falantes do português brasileiro de São Luís - MA. 2011. 248 f. Tese (Doutorado em Linguística e Língua Portuguesa) - Faculdade de Ciências e Letras, Universidade Estadual Paulista, Araraquara, 2011.

TURMA DA MÔNICA. São Paulo: Panini Comics, n. 11, março 2016.

VERGUEIRO, W. A pesquisa em quadrinhos no Brasil: a contribuição da universidade. In: LUYTEN, S. B. (Org.). Cultura pop japonesa. São Paulo: Hedra, 2005. p. 15-26.

Recebido em: 16/08/2016

Aprovado em: 18/12/2016 